\title{
Transpositions from Research into Policy and Practice: possibilities for foreign researchers
}

\author{
John Oxenham
}

\section{DISCLAIMERS}

There are a number of basic issues which this article does not address. It may help the reader to be warned of their absence.

In the first place, the words 'foreign researchers' in the title are deliberately chosen. The article is written by one who is a foreign researcher who has never been an autochthonous one in the sense of doing research on his own society and country. Accordingly, it does not presume to speak on behalf of those who form the latter category and who are well able to speak for themselves and their predicaments.

Second, it does not attempt to jusify the foreigners' rights or privileges to do research on foreign soil. It simply accepts that foreigners are allowed by many states to undertake research and similarly acknowledges that they are disallowed, or sometimes only hindered, from so doing by others.

Third, although foreigners from industrialised countries do research in other industrialised countries, their operations seem to raise neither issues nor rhetoric. So they will be ignored here. Also ignored will be foreigners from developing countries doing research in industrialised ones, for they too appear to be uncontroversial. Only foreigners from industrialised countries doing research in what are commonly labelled developing countries are considered.

Finally, I do not hold that all educational research is logically, or morally, obliged to be concerned with affecting government policy. However, I am myself so concerned. Yet I do not attempt to weigh whether foreigners have any business whatsoever to be concerned with other peoples' policies. I accept simply that many are and that interests are in turn accepted as legitimate and sometimes helpful by many societies and their governments. My thoughts then are addressed to foreign educational researchers who would like to make some contribution to educational policy and practice in developing countries and I assume the legitimacy of their positions, aspirations and operations.

\section{General Stereotypes}

Anecdotes do not make good science. Still, they can put their fingers on symptoms and stereotypes, the prevalence of which can be scientifically investigated later. So I shall use three to introduce the concern of this paper, which is the problems of foreigners as facilitators in translating educational research into educational policy and practice. A phorisms, similarly, can be unscientific but helpful. One, by an economist, is apposite here, for it fingers an almost orienting stereotype:

Practical men who believe themselves to be quite exempt from any intellectual influence, are usually the slaves of some defunct economist.

[Keynes 1964:383]

\section{The Separation of Research and Policy}

The stereotype conception is of course that the gap between new insights and understanding from research and scholarship, on the one hand, and new policies and practices among politicians, administrators and practitioners, on the other, is at least a generation wide and not susceptible to narrowing. Consequently, policy is always outdated. It acts always on less than the full potential of illumination, and researchers - along with the rest of a perhaps unaware society - have to lump it. But Keynes was writing nearly 50 years ago. He himself had effects on policies, both domestic and international, well before he was defunct. Times perhaps have changed.

\section{Mutual contempt}

However, some of his stereotypes linger in the first anecdote. A little more than two decades past, an anthropologist in what is now Zambia voiced a sharp complaint. He had carefully studied one of the many tribes of the country and felt that some of his insights might assist a wiser and less abrasive transition from 
the colonial to the new national regime. Conscientiously he committed his thoughts to a paper of nearly 100 pages. He sent the work to the Minister of Native Affairs - naturally enough a British colonial official of many years' experience and seniority, who might have been at Cambridge when Keynes was teaching there. He was - as who would not be? - incensed to hear the minister's response. The dignitary had put the report out to an assistant with this terse instruction, 'summarise in two paragraphs'.

Obviously, here is the stereotype of the policy and decision maker too impatient to let his work be informed by that of the researcher. Here is the contempt of the practical man for the merely academic. Here is the dismissal of the long-winded effusions of scholars who have nothing more important to do than scribble. Here is the implied opinion that research can at best be marginal to good government. All this notwithstanding, there is also an important shift. On the one hand, the researcher felt there might be a possibulity of informing policy. On the other, the minister did not dismiss the gesture out of hand: he just wanted the information made more easily apprehensible. The separation of institutions and the absence of communication between the $m$ are no longer absolute. Even in a developing country, even under a colonial regime, the possibility that intellectuals may have something useful to say to practical men is admitted. Elsewhere, of course, that possibility had already been more extensively realised.

\section{Disillusion}

Indeed, the second story suggests the process of realisation has gone far enough to provoke a reaction of disillusion. It dates from 1978. At a national development research conference, the chairman of an official research funding body complained, perhaps half mischievously, that social science research was really of very little use to policy, at any rate in the short term. Either the research was a large scale survey, highly representative but able to put only superficial questions and unable reliably to assess causes, effects and side effects, and so only a rather clumsy source of guidance. 'Often elegant but mostly useless' might epitomise the matter. Or the research was qualitative, rich in data and insights about a very particular and restricted sample and situation. However valid, its findings were not generalisable and ipso facto useless for general policy and programmes. Further, whichever mode of research was adopted, the time lag between research and publication rendered many of the conclusions irrelevant. The net effect was that research, so far from guiding policy, was limping behind it. Indeed, research was more formed by policy than vice versa.
However grossly simplified or caricatured these stereotypes are, they merit some attention. The official who threw out these remarks, was after all experienced in funding development research. In fact, his agency had explicitly required that those proposing research should indicate how it might assist policy. The principle that policy makers could and should continue to learn from scholars had been conceded and implemented. Indeed, the policy makers themselves had handsomely financed it. Yet here was a trumpet of disappointment. What were its sources? The explanatory hypotheses are of course several and not mutually exclusive. Perhaps the expectations of what research could achieve and how fast were too high. Perhaps the painstaking approaches and methods of scientific investigation really are inappropriate to provide the sorts and flows of intelligence that policies and decisions require. Else why would ideas and practices like 'rapid rural appraisal' come into vogue? Perhaps the conclusions of scholars really are too narrowly based in particular disciplines to be easily assimilated into the multifaceted considerations of policy. Or possibly they are too hedged with qualifications to be readily assessed for a particular situation. Perhaps, on the contrary, the fault lies not with research at all, but with policy makers, who want only such findings as will support already formed policies and programmes. Wherever the balance of probability lies, the core of discontent among both researchers and policy makers is attested in many countries, developed and developing [see, for example, Kallen et al 1982].

\section{Legitimating an intruder}

The discussion so far has implicitly assumed several areas of common ground between policy makers and researchers. Both parties are taken to have a legitimate and perhaps equal interest in the subject of policy and research. The foreign researcher, who is our concern here, has no such obvious or automatic legitimacy. $\mathrm{S} / \mathrm{he}$ needs to be sponsored. The third anecdote illustrates not simply the need for sponsorship, but also the power of what might be called a species of 'false consciousness', under which people mistake friends for hostile aliens.

The scene is again colonial Zambia in the early fifties, when the struggle for independence was gaining momentum. The particular location is the district of Kawambwa in the Luapula Valley. It is the home of the Lunda people, known to be among the more 'bolshie', troublesome and rebellious. District Commissioners had to be tough to maintain law and order. A young anthropologist resolved to study the Lunda. Taking counsel, he also resolved to steer clear of the British administration, so as not to be contaminated and suspected as a spy. On turning up at the tribal 
capital, Mwansabombwe, however, he was coolly received and for a long time was offered neither cooperation nor assistance from the Paramount Chief, elders or commoners. Eventually, he was obliged to go to the District Commissioner and obtain a letter of introduction.

The point is that, hostile as the Lundid were to the colonialists, they would not accept a white friendly and sympathetic to them, until he had been legitimated by the very authority they wanted to remove. If such an alliance could exist between colonialists and colonised, its existencne between even an oppressor regime and oppressed of the same stock in the face of foreigners would likely be more powerful yet. If that stereotype remains valid, the foreign researcher as such, and even more the foreign researcher who hopes to contribute to policy, will need sponsorship and legitimation - and not only among remote and bolshie tribesmen.

Sponsorship can of course be unconditional. However, in many countries - well developed as well as less developed - it is not. It involves negotiation and all the impedimenta of an existence dependent on the goodwill of powerful people. Behind all this, too, looms the larger question: however sponsored a foreign researcher is to do research, what really is his or her locus standi vis-a-vis policy or practice?

At this point we might pause. The anecdotes have illustrated several stereotyped problems in translating research into policy and no doubt represent some part of the truth. At the same time, they have intimated stereotypes about researchers and policy makers: there is but a single, lone researcher offering his research, a single policy maker offering his judgement on relevance and usefulness. The insinuated suggestion is of unconnected actors, of a certain homogeneity of both researchers and policy makers. Yet in education, if anywhere, there are varieties of both species, quantitatively, as well as qualitatively. And the quantities and powers of particular sorts may alter the form of an appropriate transposition from research into policy and practice, so that there are varieties of transposition as well. A moment of disaggregation might be in order then.

\section{The Spectrum of Researchers \\ Loners}

We start with researchers and bear in mind those who forage in foreign, particularly developing, countries. The lone researcher is certainly still found among us today. Doctoral candidates are a well known variety in ministries of education and in classrooms. Because they are on their own, pursuing purposes largely their own, uncommissioned by others, they can be vulnerable to arbitrary blocks and mistakes of conduct can be penalised hard. More pertinent to this paper is their uncertain status vis-à-vis policy. Most of them seem to be anxious to be of use to their host societies. Yet, officially, they have no standing, and any influence they come to wield must needs be entirely of their own personal creation. Their weakness is intensified by the rigour of academic requirements: their research is apt to be long in ripening and hence to be overtaken by events before it is published. What proportion of doctoral candidates, after all, complete their theses, publish fully matured papers or give relatively conclusive seminars on their research within three years of fieldwork? This catalogue of potential discouragements notwithstanding, loners and doctoral candidates persist as a determined and hardy species.

\section{Commissioned researchers}

Somewhat less vulnerable, though certainly not impregnable, are the academically commissioned researchers. They may not be pursuing research entirely of their own choice, although they may have had a hand in refining ideas and methods. Rather, they are the agents of other researchers and tend to operate under the aegis of two institutions, one in a developed country (and possibly the initiator of the project), the other in a developing country. The latter may have either simply acquiesced in the research and researchers, or may have collaborated in designing the research and actually asked for the researchers, because of simple manpower scarcity at home. Obviously, where such local demand obtains, the position of the researchers is firmer, if only because a local institution and local researchers have an interest in seeing the project accomplished. The possibilities are also greater for more legitimated and institutionalised links, communications and reciprocal influences with people concerned, or at least in contact with policy and practice. ${ }^{1}$ From that clearly follow possibilities of leverage - with, of course, the concomitant possibilities of leverage in mistaken directions and of finger-burning backfires. However that may be, the likelihood is that the project has been accorded sponsorship because it explicitly offers some usefulness to policy and practice. In comparison with the loner, then, the commissioned researcher has more than just a moral obligation to keep policy in mind: s/he is contractually bound to do so. However, 'keeping in mind' does not automatically confer the right - or impose any obligation - to think through the detailed implications for policy, still less to frame particular programmes, or even to mount campaigns of dissemination and discussion. The local institution may well judge that these steps are its own province, to

\footnotetext{
There are known to be regimes which have outlawed all research not explicitly legitimated by themselves, so that even their citizens need their permission. They are ignored for the purposes of this paper.
} 
be shaped in accordance with its own views of appropriateness and potential effectiveness, and best kept out of the hands of even well intentioned and competent foreigners.

\section{Employees}

The two preceding varieties of educational researcher by and large draw their finance from outside the country where they are working. They may be sponsored, but they are not employed by a local institution. The third variety is an employee or virtual employee of a local body. ${ }^{2}$ Such researchers are in a potentially stronger position than the first two, even though they remain subject of course to the weaknesses of guest workers as well as to any local restrictions or conditions on research. The prima facie legitimacy of their work is attested by the very fact of their employment. If they are with universities or research institutes, they are actually required to engage in research. The idiom of the age being what it is, research is assumed to connote relevance to some aspect of policy or practice. The nature of their sponsorship in effect confers on them a right to construct the sorts of relationships which, in one direction, inform researchers of the worries of policy makers and other practitioners - and so indicate broad areas of research - and which, in a reverse flow, can inform the practitioners more fully not only of the causes and complexities of their worries, but also of other things to add to or subtract from their worries. It is advisable to note in parenthesis that the right needs to be exercised judiciously, since even privileged guestworkers remain guest workers.

\section{Invited visitors}

Somewhere between the externally and internally employed researchers are the scholarly visitors, who in one way or another have been invited to spend some time on research and teaching. Having usually earned some prestige, they are welcome, even courted. Their potential for influencing research and perhaps policy is accordingly greater than the loners', the commissioned workers' or even the employees'. On the other hand, it is more restricted than that of the employees, simply because visits tend to be short and research projects necessarily modest in scope.

\footnotetext{
2 The term virtual had better have its connotation explained immediately. A number of people in the government services, universities, research and educational institutes of a country are employed and paid by external agencies. Nevertheless, they are responsible for their day-to-day work to their local institutions and subject to their priorities, even while they remain partially responsible to and partly protected by their paying agency. These are termed virtual employees. Others are recruited and employed directly by local institutions, but may have portions of their emoluments met by outside agencies. They are regarded simply as employees.
}

\section{Researcher-cum-advisers}

A good deal more directly linked to policy and hence potentially more powerful is another kind of visitor. These are also invited, also have prestige as researchers, but they in addition straddle the borders between research and advice or consultancy. Particularly spectacular examples are the international commissions to advise on educational reorganisation or reform. However, there are many more modest instances, some involving only a single foreign researcher-cum-adviser, beavering in almost complete obscurity. Although such people work to relatively specific remits, their very tasks require research, often quite extensive and innovative - and indeed of ten 'quick and dirty', but helpful nonetheless.

On the other hand, there is a noteworthy peculiarity in this category of researcher. To be sure, their advice is tailored to research done in a particular country, possibly at their particular request and to their particular design. At the same time, the span allotted for both research and advice is usually very short. Consequently, even necessarily, the new research has to be ingested into orientations formed largely and over longer periods by research and reflection elsewhere. Thence arises the ironic possibility that the foreigners least steeped in a particular situation may have the most powerful opportunities for influencing it. $^{3}$

\section{Politics and the hiding hand}

This observation helps bring some latent points out. First is an assumption underlying the very thought of categorising researchers not by type of research survey, anthropological, statistical - but by status. The emphasis on persons - foreigners sponsored by tolerance, formal collaboration, employment, invitation or prestige - insinuates that the connections between research and policy hinge on personal relationships and influences and are in that sense political. By corollary, it insinuates that researchers without such political relationships reduce whatever hopes they may have to affect policy and practice. By extension, it suggests that the impact of research on policy and practice is not direct and cannot be taken for granted. On the contrary, competition for

${ }^{3}$ This kind of foreign researcher-cum-adviser is notably absent in the developed countries and is growing rarer in the educationally more advanced developing countries. They are apparently a phenomenon of the transition to educational self-sufficiency, and as such could be one of the symptoms of dependency. Let me hasten to stipulate, however, that dependency here connotes a state that is neither necessarily repugnant nor perpetual. It indicates merely that a government (or a fraction of a government) is dissatisfied with some aspects of education, wishes to alter it and either recognises or acquiesces in a view that its own resources are not sufficient for the purpose. Indeed, the hypothesis might well be posed for that recognition of a degree of dependence might assist the crossfertilisation and regeneration of education in the developed countries. 
attention, communication, mediation, interpretation, argument and sheer personal credibility are all inferred to be ingredients in the translation from findings to eventual behaviour. These are of course general assumptions, applying equally to indigenous and foreign researchers. Their salience is simply more acute for the foreigner.

However, there is no assumption that direct personal connections are the only way to ensure connections between research and policy. On the contrary, the second point, latent in the researcher-advisers, is the 'hiding hand' of research and scholarship. Several syntheses of research done in several countries prove to have some relevance for the circumstances of yet another society, not even thought of at the time of the original experiences. Those syntheses have, as Carol Weiss [1982] put it, altered the terms of discourse, the frameworks of thinking in a general sense. The Lord may move in mysterious ways. So too do the ripples and repercussions of research.

By no means does this affirmation deny the fallibility of random ripples. Insights into one educational system and its society may well be inapplicable elsewhere. Regret, if not injury, may follow mistaken application. Yet the point remains that immediate personal connections are not the exclusive channels for informing policy with research. Accummulating research capital may yield returns in unexpected circumstances for unexpected clienteles. Which is to urge loners and commissioned researchers, who feel they lack status, and employees who feel they are not heard, not to despair at their hosts' apparent short term indifference to their discoveries.

\section{International Support and its Trade-offs}

The third point is the looming background presence of international and aid agencies. However much they attempt to disappear into the scenery, they remain as vital as the air for foreign researchers in developing countries and, with variation, even for research itself in developing countries. Loners, commissioned researchers, virtual employees, visitors as well as researcher-cum-advisers all depend on, or rather are enabled by, these bodies to do their research. More significantly, without these bodies, many developing countries would have their educational research efforts substantially curtailed. Equally important are three corollaries of the function of financial support.

On one side, because their resources, like most people's, are limited, they have to select what they support and what they decline to support. This entails their forming criteria for preferences and, by that action itself, defining what is more and what is less important to be researched in education. In so doing, they constitute willy nilly a simultaneous market, guide and control, by which researchers in quest of support have to modulate what they say they want to do. To offset the negative shade, it is as well to remark that the criteria of preferences are formed neither arbitrarily nor in aloofness, but largely in consultation with both researchers and practitioners. Even so, they remain inescapably a restriction on the judgements of researchers and must needs be accepted as the lesser of two evils. For the worse evil is the disappearance of the funds, along with the vanishing of all choice. The hope must be that, although there will likely be some convergence of thought among the various bodies and some sort of 'establishment', there will yet remain sufficient divergence to provide a true market for the persevering researcher: somewhere among them will be one whose criteria coincide with the researcher's perceptions.

On a second side, the preferences of these bodies unavoidably signal to practitioners in developing countries. Whether or not the latter take notice of the signals will presumably depend on the degree to which they can do without the aid of either funds or researchers, or on their confidence in their own programmes. Whatever their stance, they are likely to be more willing to permit access to researchers sponsored by these agencies, on the twin grounds of probable value and maintaining good relations.

For the purpose of this paper, however, the third aspect, which proceeds from the first two, is salient. For these bodies are of course influences not only on research: they have persistent, often heavy, impact on policy and practices as well. For one thing, they constitute amplifiers, through which new research is enabled to alter climates and frameworks of thinking much more rapidly than when Keynes was writing. Their publications, symposiums, workshops, conferences, courses, accelerate the processes of diffusion, awareness, ingestion. They may simultaneously engender fads, shallow slogans and half-baked projects, but that perhaps is part of the price of trying to achieve swifter and more efficient improvements in education. Whatever the balance of view here, these bodies remain important to foreign researchers, and not just for support. They are an almost indispensable medium of communication to particular audiences as well as to general publics of practitioners. Indeed, where there is a close coincidence of interest between an agency and a researcher, a project can be designed to carry matters from field research through preliminary publication to intensive meetings with varieties of policy makers and practitioners and from there to final publications influenced by the considerations of the practitioners. While even such a project does not assure immediate effects upon practice, it perhaps at least helps clear the air and paths for change. 


\section{Locus of initiative}

In the discussion there has been a continuous shift in what might be called the locus of initiative. The opening focus was on the researcher or research institute as progenitor of investigation. Then came the applying body which selected researcher-cum-advisers to apply previous research - or to generate new research - to new, partly strange situations. That is, former research initiatives by researchers evoke research-using policy initiatives by practitioners. Third came the acknowledgement that part of the initiative was unavoidably taken by funding agencies in their criteria of preference. Just now came the example of a kind of joint initiative between funding body and researchers. The next step in the spectrum seems evident.

So far the traditional separation between scholars and practical men has persisted, even if it has been attenuated. The next step is to close it altogether by uniting researchers and policy makers in one institution. Initiatives for both research and policy can be undertaken by a single agency. It need not await and adjudicate among proposals for research. Instead, it frames its own and, if necessary, engages nonmembers to carry them out. Neither need it content itself with changing climates and frameworks of thinking, though it undertakes this, too. It can go further and use its power to finance policy and programmes as an open lever on practice. Also, because by present definition it is an international organisation operating among a multitude of countries, most of its research, interpretation and application would have necessarily to be done by foreigners. A example of this apparent interpretation of research and policy making, which springs most readily to mind is the World Bank.

This is not to assert that the power of the lever is absolute. On the contrary, it is subject to softening in negotiations with governments and particular circumstances, and subsequently to heavy dilution in actual implementation by a range of far-flung, not easily controlled practitioners. Further, within the institution itself, the researchers are not necessarily the sole or even the most influential determinants of how research should mould policy. Within bureaucracies there are territories, spheres of influence, impermeabilities which slow and sometimes frustrate the ripples of research. That notwithstanding, the researcher within a body which both needs its own research and actually finances educational reform seems clearly in a more immediately and widely advantageous position than the loners or even the researcher-cum-advisers.

Another point may be worth making. It is possible that an agency intimately entangled with policy might tend to confine itself to the sorts of research which can yield quick intelligence about pressing problems and short term trends. Such a preoccupation might well steer it away from fundamental issues, so that its impact on education could be reduced to marginal trimmings. On the other hand, the actual record of the institutions which do exist suggest that such fears, while valid in principle, have largely not been borne out. The mix of research that is published seems as much concerned with improved basic understanding, as it is with immediately usable intelligence.

The fear expressed in the preceding paragraph is akin to another about the propriety and danger of an organisation which combines research, policy formulation and financial power. On the general plane, sealing the institutional gap between researchers and policy makers may seem desirable in idea, but is it empirically healthy for researchers? Would it not be wiser to keep the two separate, even within national societies, but improve and intensify communication between them? Or possibly arrange for regular alternations of role?

On the particularly international plane, the sources of additional anxiety are at least three. In the first place, the researchers of such an organisation will necessarily be limited. Yet, because they may be all that is available, they may be used - in the alleged fashion of the IMF - to formulate policies for universal application. They will in effect be the base of a procrustean bed for the injury of education around the world.

Allied is the issue of the maturation of research. A gap of a generation between initial finding and ingestion into policy may indeed be excessive. At the other extreme, no gap at all may necessitate overhasty interpretation and the neglect of important ramifications. A judiciously controlled gap may protect the interests of researchers, policy makers and patients alike. The proclivity for speed in an organisation concerned with policy and programmes coupled with the pressure on the research branch to justify itself, is likely to override the desirability of the gap.

Second, the organisation's financial power will enable it to impose, or gain acquiescence for its views, whatever the reservations of local educators. Their need for finance may well override and muffle their professional objections. The financial power could of course influence areas and approaches to research, as much as policy. Only questions, only methods judged valid by a reigning group or establishment of researchers might become acceptable and thence fashionable. A powerful conservation could set in and through a process of self-perpetuation distort the development of policy oriented research around the globe. 
Third, its capacity for injury will lack bridle, for it is essentially responsible only to itself. It is not accountable to those who accept its money and try to implement its recommendations. Still less is it answerable to those on whom its recommendations are practised. In short, sealing the institutional gap may generate worse problems than it cures. Further, the aggravation may be worse on the international plane, than on the purely domestic. ${ }^{4}$

All these hesitations have a certain force. Yet at the same time they can be opposed by the old scholastic principle, abusus non tollit usum, misuse does not invalidate use. All human institutions are liable to abuse and distortion: that can be taken as axiomatic. The issue then is not whether they should exist, but whether their regulation provides sufficient safeguard against misuse. A pragmatic view would edge further and suggest that safeguards cannot insure against all misuse, but can merely restrain it to tolerable levels. That involves accepting choices between possible evils. Is greater potential loss or damage likely to flow from the continued formal separation of research, funding and policy or from trying to overcome loss and delay by combining the three functions in one influential body? Is it not the case that combinations are being attempted precisely because the measures to counterbalance the ill effects of separation have been judged insufficiently effective - as the second anecdote suggested? On balance, it would appear that a potentially more fruitful way forward would be promoting new arrangemnts - but simultaneously safeguarding against possible abuses. The alternative of attempting to devise even more expedients to keep two disparate groups of workers in constant and effective communication with each other, seems already exhausted.

A final coda to this section of the discussion is the observation that, even in a single 'combined' institution, research does not seem to swing policy and programmes into different courses immediately. The 1974 and 1980 Education Sector Papers [World Bank 1974, 1980] seem to bear that out. However anxious and hasty researchers may be to affect policy, then, some kind of 'momentum' gap has to be accepted as endemic and possibly irreducible. Conversely, the magnitude of the gap will tend to be inversely proportionate to the legitimated standing of foreign researchers among their peers, aid organisations and the policy makers with whom they may work.

The shift of initiative also underlines two long obvious facts and in so doing sends a long obvious signal to

\footnotetext{
4 Informing these fears are of course cautions about the ideological stances and preferences of international institutions and the implications for the kind and thrust of the research that gets done. They will not be considered here
}

foreign researchers. One fact is simply that educational policy is no longer solely a domestic concern and has not been, ever since international agencies and international aid came on the scene. ${ }^{5}$ There is of course a well known imbalance. The educational policies of the industrialised states may be of interest to each other, as well as to researchers in developing countries. However, the interest is mainly academic, inasmuch as there seems to be little attempt to celebrate mutual influence. Each industrialised educational system does make itself available to be studied and crossfertilisation is encouraged. Nonetheless, advice on policy is neither offered nor sought. In contrast, the educational policies of developing societies attract sought and unsought counsel in interminable streams and get it still mainly from the industrialised countries. The flow of interest may be two-way, but the flow of advice is certainly not. ${ }^{6}$ Indeed, the industrialised states take little, if any, advice even from the organisation which they in the main fund to develop advice.

\section{International aid agencies and researchers}

The second obvious fact is that the aid agencies, both national and international, are still unable to meet all their commitments from their own stocks of permanent or quasi-permanent personnel. They still need to buy in expertise - although the global recession and the actions of some governments have reduced their current capacity to do so. As is well known, their chief sources are universities and research institutes. The national agencies tend to stick to their national sources - though there are of course prominent exceptions - while the international can and do take the world as their oyster. Either way, the result is that these organisations have become major instruments for closing the gap between research and policy, and indeed for maintaining a constant and wide process of cross-fertilisation. Whatever the degree of disillusion and cynicism about them - like all other human institutions, they are naturally subject to error, abuse and corruption - these agencies have attained a pivotal position in promoting mutual relevance between research and policy.

From this comes the signal long obvious to researchers confident enough to want to help form policy for societies not their own. To optimise the probability - and the rate - that their research will feed widely

\footnotetext{
${ }_{5}$ An argument might indeed be made that educational policy was 'internationalised' at least a century ago by western Christian missionaries and the colonial empires. I refrain from pursuing it here.

- Of course, the participation of developing count ries in organisations like UNESCO and the increasing numbers of experts and consultants from them make this statement less true than it used to be. Nevertheless, in regard to 'pure' or independent researchers, it probably remains a tenable generalisation
} 
into the processes of policy making. they should take care to feed it also to these agencies. ${ }^{\text {? }}$

A nother pragmatic point argues for foreign researchers to forge and persist with links or channels to international and aid agencies. It is the mismatch between the nature of policy making and practiceforming processes and an almost inevitable characteristic of foreign researchers. Policy making is ongoing. perpetual. To change policy requires either shocks or persistence over the long haul. Foreign researchers, on the other hand. are by and large transitory. They have a necessarily - and properly - limited currency and impact. Therefore, a drive for momentum should be built up in an institution which can at once ingest research information and bring it to bear persistently and through many media on enduring institutional relationships with educational systems.

\section{Conclusions}

What inferences might follow from the fables. categorising and discussions? In the developed countries. foreign educational researchers do not expect, nor are they expected, to contribute to policy. They are expected simply to get on with research and scholarship. In developing countries, on the other hand. such researchers seem to feel obliged to justify themselves by somehow being of use to their host societies. The information and insight they generate should somehow assist policy. Otherwise. their research might be seen as a form of cultural or academic imperialism. Yet their position as temporary guests, investigating a necessarily small section of reality, means that they have not the time nor the resources to offer more than a few pieces of understanding to a complex and changing whole. Perhaps then their stance vis-a-a-vis policy should be modest to the point of reticence. They might content themselves with three expedients. First. for possible short term benefit. particular pieces of research and their conclusions might be submitted in easily absorbed forms to appropriate practitioners. policy

\footnotetext{
? Jibes about the pecuniary potential of such a convenient marriage of good intent and professional work. doing oneself good by doing good to others, readily suggest themselves, of course. There is no need to counter them. Even so, two questions can be pertinently counterposed. Do mixed motives necessarily invalidate an action? Is the evil of being misunderstood - or even all too well understood! - greater or less than the evil of letting useful knowledge languish through neglect?
}

makers and their institutions, to be ingested as the latter deem convenient. Second, to affect the terms of discourse. the researches should be published for the educational research community. both indigenous and global. for ingestion into the general understanding of education. Finally, they might seek to establish themselves as reputable scholars as resources for the international and aid agencies: the understanding generated by their research in one or even several countries may eventually help improve education in a country as yet untouched by them.

\section{References and bibliography}

Carron. G.. 1977. Some Thoughts on the Relationship between Research and Decision-Making, reports. studies. S.47. Division of Educational Policy and Planning. UNESCO. Paris

Green. R. H. G.. 1983. 'Through some looking glasses: reflections on economic planning in academies. plazas and corridors of power. Institute of Development Studies. Sussex. mimeo

Heyneman. S., 1980. 'Reserch on education in the developing countries'. World Bank Education Department. Washington, mimeo: and International Journal of Educational Development. forthcoming

Kallen. D. B. P., G. B. Kosse. H. C. Wagenaar. J. J. J. Kloprogge. M. Vorbeck (eds). 1982. Social Science Research and Public Policy-Making: a reappraisal. NFERNelson and SVO Foundation for Educational Research in Netherlands. Windsor

Keynes, J. M.. 1964. General Theory of Employment, Interest and Money. Macmillan. London

Prospects. 1981. 'Elements for a dossier: educational research for development'. vol XI no 3. pp305-80

Weiss. C. H.. 1982. 'Policy research in the context of diffuse decision making'. in Kallen et al. op cit. pp288-304

World Bank. 1974. Education Sector Working Paper. Washington

-1980, Education Sector Policy Paper. Washington 